PROGRESS REPORT

\title{
A NOVEL PROCESS FOR METHANOL SYNTHESIS
}

\author{
Principal Investigators \\ John W. Tierney \\ Irving Wender
}

\begin{abstract}
Chemical and Petroleum Engineering Department
University of Pittsburgh

Pittsburgh, PA 15261.
\end{abstract}
Prepared for the Department of Energy
Grant No. DE-FG22-89PC89786

December 1, 1992 through February 28, 1993

\section{DISCLAIMER}

\begin{abstract}
This report was prepared as an account of work sponsored by an agency of the United Staies Government. Neither the United States Government nor any agency thereof, nor any of their employees, makes any warranty, express or implied, or assumes any legal liability or responsibility for the accuracy, completeness, or usefulness of any information, apparatus, product, or process disciosed, or represents that its use would not infringe privately owned rights. Reference herein to any specific commercial product, process, or service by trade name, trademark, manufacturer, or otherwise does not necessarily constitute or imply its endorsement, recommendation, or favoring by the United States Government or any agency thereof. The views and opinions of authors expressed herein do not necessailiy statc or reflect those of the United States Government or any agency thereof.
\end{abstract}

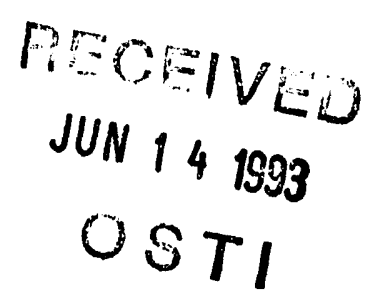

MASTER 


\section{TABLE OF CONTENTS}

1.0 ABSTRACT

1

2.0 INTRODUCTION

2

3.0 RESEARCH OBJECTIVES

4

4. 0 CURRENT WORK

5

5.0 FUTURE WORK

6.0 REFERENCES

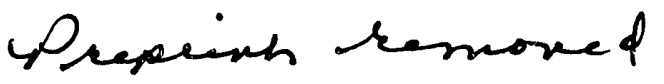




\subsection{ABSTRACT}

A bench-scale reactor is being used to conduct studies of the conversion of synthesis gas to methanol (MeOH) in the liquid phase by a novel process. In previous reports, we provided evidence for a two step reaction in series, the carbonylation reaction mainly taking place close to the copper chromite surface, and the hydrogenolysis reaction taking place on the surface of the copper chromite. The interaction between the two catalysts enhances the rate of $\mathrm{MeOH}$ formation. We have previously shown that under present operating conditions, the methyl formate (MeF) concentration is not in equilibrium. The presence of $\mathrm{H}_{2} \mathrm{O}$ results in a drop in the rate of MeF generation by the carbonylation reaction. In this quarter, we examined schemes to reduce the $\mathrm{H}_{2} \mathrm{O}$ level in the reactor and enhance the rate of MeF formation. An increased MeF concentration would lead to increased MeOH synthesis rates. The final report for this project is also under preparation. A paper was presented at the Spring Meeting of the AIChE in Houston, TX. A copy is attached. 


\subsection{INTRODUCTION}

An experimental investigation of a new synthesis, developed in our laboratory, for converting synthesis gas to $\mathrm{MeOH}$ is being carried out. It has advantages over the conventional gas phase synthesis in that the recycle of unreacted material can be virtually eliminated and it operates at lower temperatures. The reaction is tolerant to small amounts of $\mathrm{CO}_{2}$ or $\mathrm{H}_{2} \mathrm{O}$. It has been demonstrated that the reactions proceed with good rates at $150^{\circ} \mathrm{C}$ and 63 bar pressure. We have previously provided evidence for the formation of MeOH proceeding through MeF in this concurrent synthesis. However, the nature of the mixed catalyst, comprised of an alkali methoxide (e.g. KOMe) and copper chromite and of the possible intermediates is not well understood. The thrust of this research program is to obtain a better understanding of the reaction and particularly of the role of the catalyst(s). This information should help make it possible to scale up the process.

Four papers have been prepared ${ }^{(1-4)}$ reporting our studies. The first paper is a study of the individual consecutive reactions: carbonylation of $\mathrm{MeOH}$ to MeF followed by the hydrogenolysis of the MeF. The other papers describes the concurrent reaction in which a carbonylation catalyst (e.g. KOMe or other soluble alkali catalyst) and a hydrogenolysis catalyst (e.g. copper chromite) are used in the same reactor. One more paper is under preparation. The current 
work is part of a three and a half-year project which started in September, 1989. During this quarter, a paper was submitted for presentation at the AIChE Spring Meeting in Houston, TX, March 28April 1, 1993. A copy of that paper is attached.

In this report, a soluble catalyst refers to an alkali compound (e.g. KOMe) added as a powder to the reactor (the powder is soluble in $\mathrm{MeOH})$; the copper chromite is referred to as a heterogeneous catalyst. A "homogeneous" reaction is thus one which takes place in the liquid solution (not on the surface of copper chromite) and a heterogeneous reaction is one which takes place on the surface of copper chromite. It is possible that the soluble salt is adsorbed on the copper chromite and the combination then functions as the catalyst or the catalyst precursor. 


\subsection{RESEARCH OBJECTIVES}

Principal research objectives are,

1) To determine the effect of various catalysts on the synthesis of MeOH.

2) To determine the nature of the active catalyst in this reaction and the effect of deactivating agents such as $\mathrm{CO}_{2}$ and $\mathrm{H}_{2} \mathrm{O}$.

3) To determine the rate-limiting step(s) in this reaction. The effect of catalyst loading and reactor volume are of special importance.

4 ) To develop mathematical models which can be used to predict the rates of reaction and could be useful in eventual scale-up of the reaction. 


\section{0 CURRENT WORK}

Schemes to reduce the $\mathrm{H}_{2}()$ concentration in the reactor and boost MeF formation rates are examined in this report. We have previously reported that the $\mathrm{H}_{2} \mathrm{O}$ concentration in the reactor is limited by its formation by the reaction involving dehydration of MeOH. The use of a solvent other than MeOH could result in reduced $\mathrm{H}_{2} \mathrm{O}$ concentration. It is hoped that this would increase the rate of MeF formation enhancing the rate of MeOH formation.

\subsection{Effect of Cyclohexane as Solvent in the Concurrent Synthesis}

The rate of the concurrent $\mathrm{MeOH}$ synthesis is influenced by the rate of MeF formation by the carbonylation reaction. The nucleophilicity of the methoxide anion (the active catalyst) is known to be a function of the hydrogen bonding capability of the solvent. It is reported that the presence of a protic solvent such as MeOH renders the methoxide anion less nucleophilic due to the hydrogen bonding ability of the hydrogen in the 0-H group in MeOH to the nucleophilic methoxide anion(5). The presence of alkali cations is believed to decrease this hydrogen bonding(5). Onsager et al. (6) claimed that the use of a solvent with a lower dielectric constant than $\mathrm{MeOH}$ helped increase the rate of MeOH synthesis. They reported up to $50 \%$ increase in the rate of MeOH formation using cyclohexane $(\mathrm{CH})$ as a solvent. Two possibilities can account for 


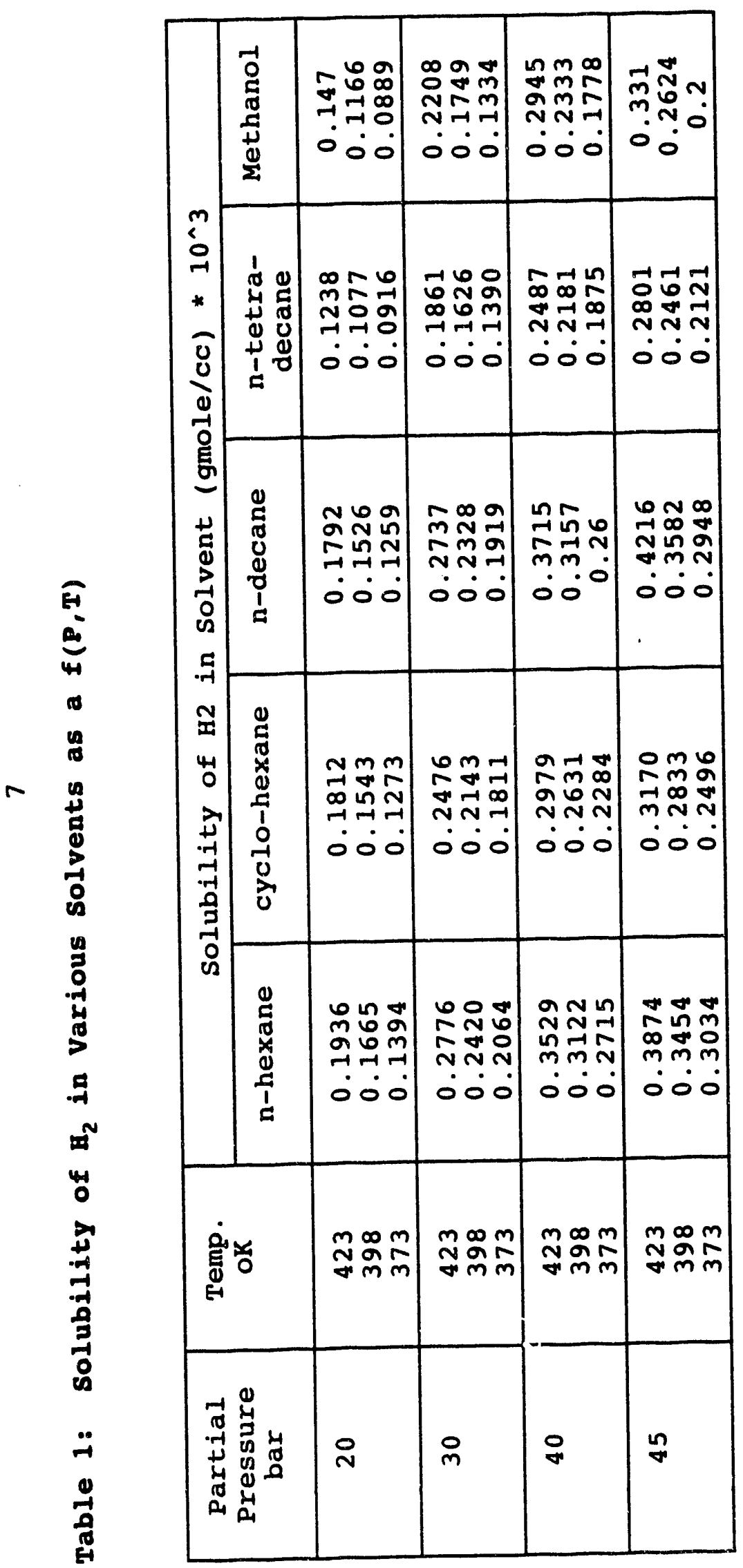




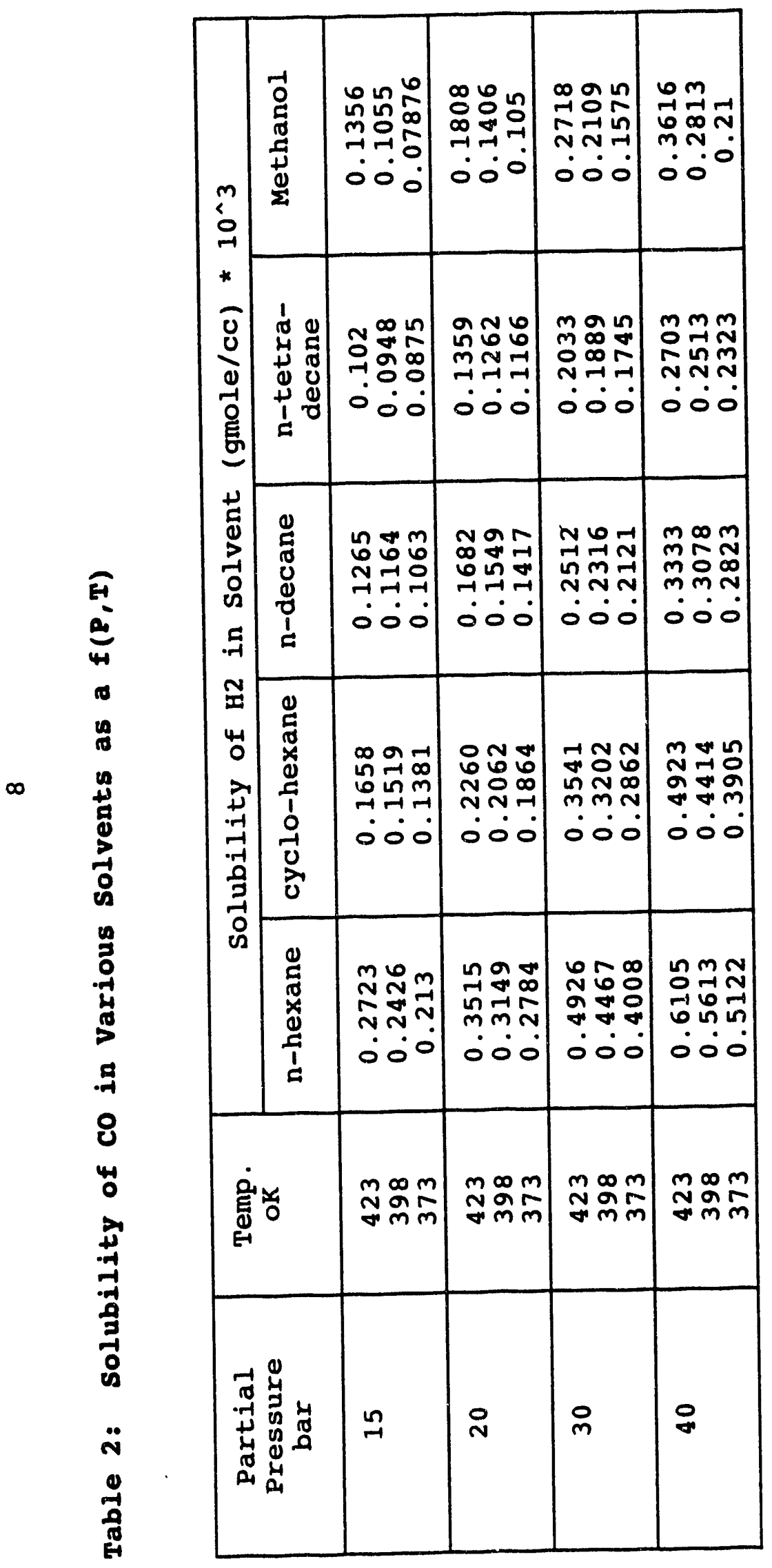


the increased rates -- one is the reduced hydrogen bonding ability and another is the increased solubility of the reacting gases co and $\mathrm{H}_{2}$ in these solvents. The solubilities of $\mathrm{H}_{2}$ and $\mathrm{CO}$ in different solvents were calculated using the equation of Chang et al. $(6,7)$. Indeed as shown in Table 1 and 2 , the solubilities of $\mathrm{CO}$ and $\mathrm{H}_{2}$ are higher in a variety of aprotic solvents (lower dielectric constants).

We tested the activity of the kOMe/copper chromite catalyst system in $\mathrm{CH} / \mathrm{MeOH}(2: 1)$ as solvent at 63 atm total pressure and a feed $\mathrm{H}_{2} / \mathrm{CO}$ ratio of one. As shown in Table 3 , the activity in a pure $\mathrm{MeOH}$ solvent is higher than in a $\mathrm{CH} / \mathrm{MeOH}$ solvent. This was obviously due to the lower $\mathrm{CO}$ and $\mathrm{H}_{2}$ partial pressures, due to the higher volatility of $\mathrm{CH}$. The lower $\mathrm{CO}$ partial pressure resulted in a lower MeF concentration. At constant total pressure, the effect of the use of $\mathrm{CH}$ as solvent on MeOH synthesis activity is contrary to that of Onsager et al. (8) who reported almost a 508 increase in MeOH formation activity. If the $\mathrm{CH} / \mathrm{MeOH}$ solvent can be used at the same partial pressure as that of pure MeOH in Table 3, increased rates of MeOH formation could probably be obtained. This would require the use of a higher operating total pressure (in the range of 75 atm).

The lower hydrogen bonding capacity and increased solubility of aprotic solvents can however be taken advantage of by using a 
high boiling solvent such as triglyme. This scheme as well as the use of solvents such as higher alcohols is presently being examined.

Table 3: Rate of Methanol Synthesis in Cyclohexane/Meol as Solvent

\begin{tabular}{|c|c|c|c|c|}
\hline Solvent & $\begin{array}{c}\text { Conc of } \\
\text { Methyl Formate } \\
\text { in Liquid } \\
\text { (Experimental) } \\
\text { (moles) }\end{array}$ & $\begin{array}{c}\text { Equilibrium } \\
\text { Conc of } \\
\text { Methyl } \\
\text { Formate in } \\
\text { Iiquid } \\
\text { (moler) }\end{array}$ & $\begin{array}{c}\text { Rate of } \\
\text { Methanol } \\
\text { Synthesis } \\
\text { (moles/h/ } \\
\mathrm{kg} \text { cat) }\end{array}$ & $\begin{array}{c}\text { Partial } \\
\text { Pressure } \\
\text { (bar) }\end{array}$ \\
\hline $\begin{array}{c}\text { Methanol/ } \\
\text { Cyclohexane } \\
(1: 2)\end{array}$ & 2.36 & 2.94 & 14.98 & 10.63 \\
\hline Methanol & 5.2 & 6.28 & 19.5 & 23.45 \\
\hline
\end{tabular}

Feed $\mathrm{H}_{2} / \mathrm{CO}=1, \mathrm{~T}=150^{\circ} \mathrm{C}, \mathrm{P}=63$ atm

\subsection{Effect of Increased Amount of Heterogeneous Catalyst}

Increasing the amount of heterogeneous catalyst should result in increased reaction rates. However, a three-fold increase in the copper chromite loading resulted in only a $26 \%$ increase in the overall reaction rate (moles/min) with a 348 decrease in the concentration of MeF. The results are summarized in Table 4. Evidently, the increased rate of hydrogenolysis due to the increased amount of copper chromite was negated by a decrease in MeF concentration. 
11

Table 4: Effect of Increased Amount of Copper Chromite on the Concurrent MeOB Synthesis

\begin{tabular}{|c|c|c|c|}
\hline $\begin{array}{c}\text { Copper } \\
\text { Chromite } \\
\text { Loading } \\
\text { g/l }\end{array}$ & $\begin{array}{c}\text { Kome Loading } \\
\text { moles/1 }\end{array}$ & $\begin{array}{c}\text { MeF Conc in } \\
\text { Liquid } \\
\text { moles }\end{array}$ & $\begin{array}{c}\text { Rate of MeOH } \\
\text { Synthesis } \\
\text { moles/min } \\
\star 10^{4}\end{array}$ \\
\hline 20 & 0.048 & 1.79 & 7.5 \\
\hline 60 & 0.048 & 0.59 & 9.45 \\
\hline
\end{tabular}

- Equilibrium MeF concentration at $150^{\circ} \mathrm{C}$ and $63 \mathrm{bar}=3.1$ molez.

An interesting effect was observed in the above experiment, at steady state, when $0.5 \mathrm{~g}$ KOMe (dissolved in $20 \mathrm{cc}$. Of fresh MeOH) was injected into the reactor. As shown in Figure 1, the rate of MeOH synthesis increased significantly with a concomitant increase in MeF concentration. The point of injection is referred to as time $=0$. Obviously, the increased concentration of kome led to higher MeF concentration, resulting in enhanced MeOH rates. The effect of an increased KOMe concentration in situ is the same as that of a lower $\mathrm{H}_{2} \mathrm{O}$ concentration. The rate of MeOH formation as well as $\mathrm{C}_{\text {Mef }}$ was found to decrease with time, as shown in Figure 1. This is in support of our proposal that a lower $\mathrm{H}_{2} \mathrm{O}$ concentration should enhance MeOH rates. 


\subsection{FUTURE WORK}

Further studies to evaluate strategies for increasing the carbonylation rate and hence the rate of $\mathrm{MeOH}$ formation are currently being examined. The effect of solvent on methanol formation rates will be investigated. The final report for this project is under preparation. 


\subsection{REFERENCES}

1) Z. Liu, J. W. Tierney, Y. T. Shah and I. Wender, Methanol Synthesis via Mothyl Formate in a Slurry Reactor, Fuel Processing Technology, 23, 1989, p. 149-167.

2) Z.Liu, J. W. Tierney, Y. T. Shah and I. Wender, Kinetics of the Two Step Methanol Synthesis in the Slurry Phase, Fuel Processing Technology, 18, 1988, p. 185-199.

3) V. Palekar, H. Jung, J. W. Tierney and I. Wender, Slurry Phase Synthesis of Methanol with a Potassium Methoxide/Copper Chromite Catalytic System, submitted for publication in Applied Catalysis.

4) V. Palekar, T. W. Tierney and I. Wender, Alkali Compounds and Copper Chromite as Catalysts for a slurry Phase synthesis of Methanol, submitted for publication in Applied Catalysis.

5) R. J. Msayib and C. I. F. Watt, Ion Pairing and Reactivity of Alkali Metal Alkoxides, Chemical Society Reviews, 1992, p. 237-243.

6) M. Chang, G. Eiras and B. Morsi, Mass Transfer Characteristics of Gases in $n$-Hexane at Elevated Pressures and Temperatures in Agitated Reactors, Chem. Eng. Process, 29, 1991, p. 49-60.

7) M. Chang and B. Morsi, Mass Transfer Characteristics of Gases in n-Decane at Elevated pressures and Temperatures in Agitated Reactors, The Chemical Engineering Journal, 47, 1991, p. 33-45.

8) 0. T. Onsager, Method for Production of Methyl Formate and Methanol, Canadian Patent No. 1,175,798, assigned to Sintef, Norway, 09/10/1984. 


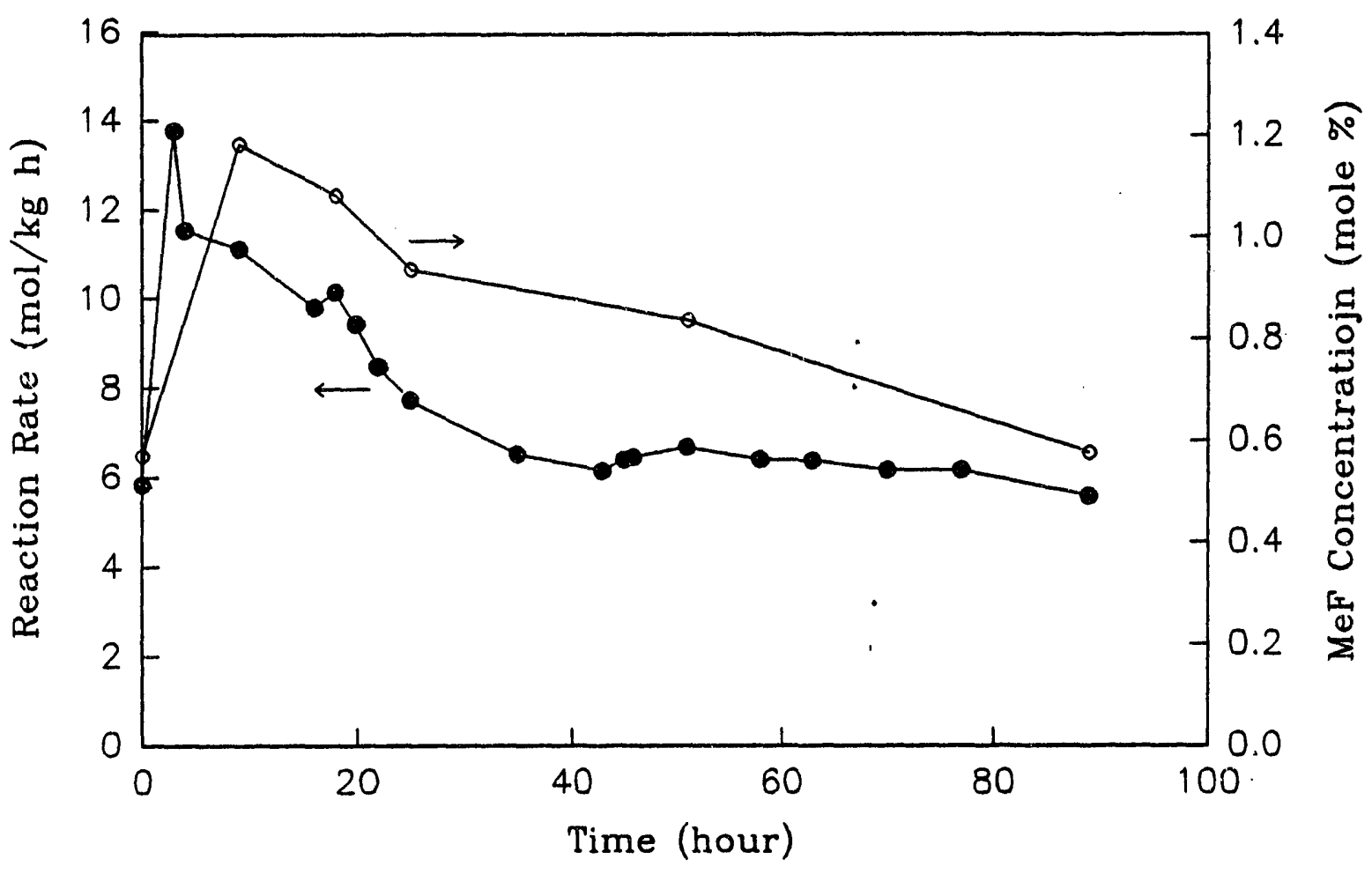

Figure 1: Bffect of addition of ROMe 

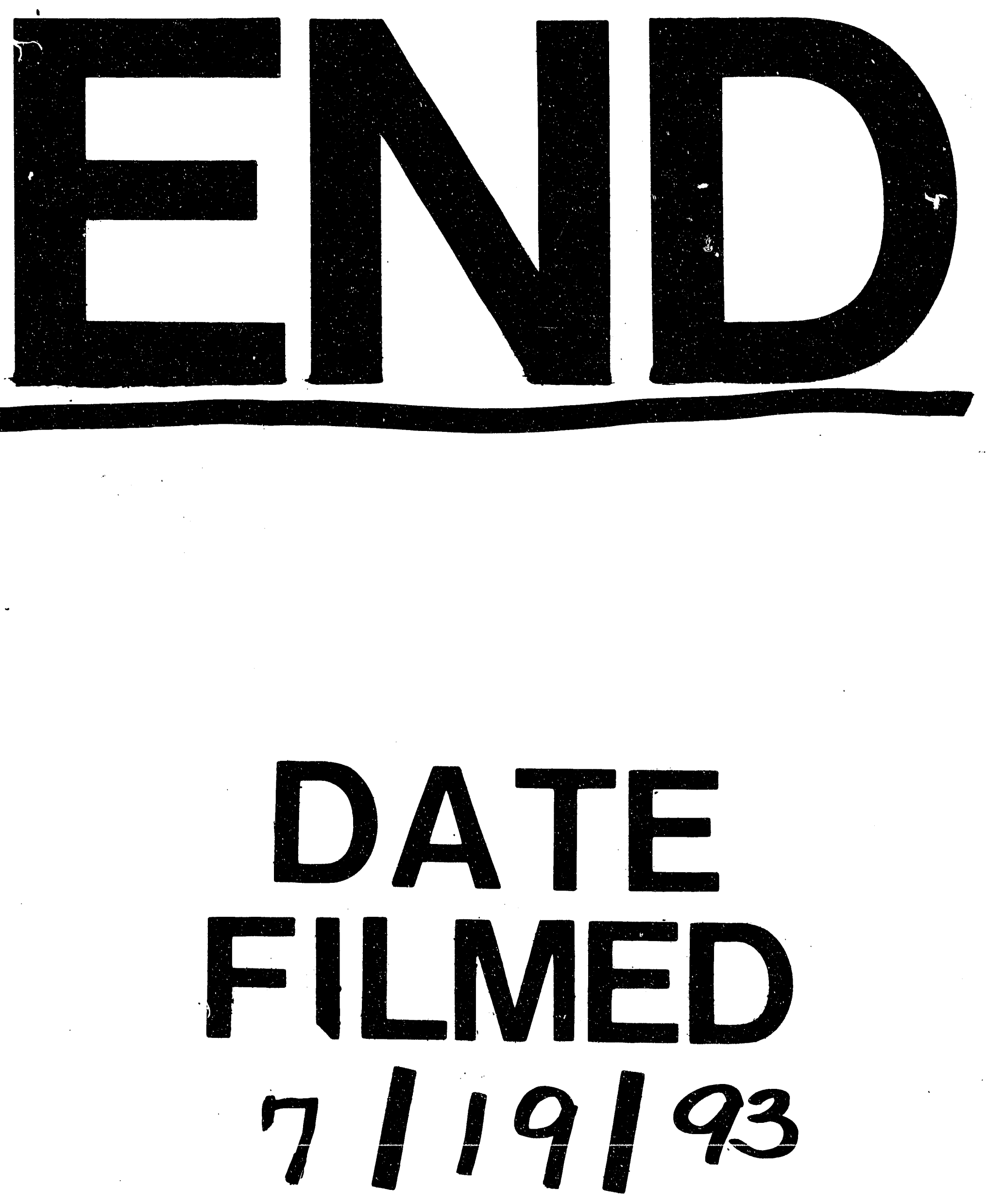
